2000. Combining structure-based design with phage display to create new $\mathrm{Cys}_{2} \mathrm{His}_{2}$ zinc finger dimers. Structure 8:739-750.

11.Choo, Y. and A. Klug. 1994. Selection of DNA binding sites for zinc finger using rationally randomized DNA reveals coded interactions. Proc. Natl. Acad. Sci. USA 91: 11168-11172

12.Wu, H., W.-P. Yang, and C.F. Barbas III. 1995 Building zinc fingers by selection: toward a therapeutic application. Proc. Natl. Acad. Sci. USA 92:344-348.

13.Bulyk, M.L., X. Huang, Y. Choo, and G.M. Church. 2001. Exploring the DNA-binding specificities of zinc fingers with DNA microarrays. Proc. Natl. Acad. Sci. USA 98: 7158-7163.

14.Ausubel, F.M., R. Brent, R.E. Kingston, D.D. Moore, J.G. Seidman, J.A. Smith, and K. Struhl. 1990. Expression using the T7 RNA polymerase promotor system, p. 16.2.116.2.11. In Current Protocols in Molecular Biology. Wiley-Interscience, New York.

15.Krizek, B.A., B.T. Amman, V.J. Kilfoil, D.L. Merkle, and J.M. Berg. 1991. A consensus zinc finger peptide: design, high-affinity metal binding, a $\mathrm{pH}$-dependent structure, and a His to Cys sequence variant. J. Am. Chem. Soc. 113:4518-4523.

16.Choo, Y. and A. Klug. 1993. A role in DNA binding for the linker sequences of the first three zinc finger proteins of TFIIIA. Nucleic Acids Res. 21:3341-3346.

17.Berg, J.M. 1992. Sp1 and the subfamily of zinc finger proteins with guanine rich binding sites. Proc. Natl. Acad. Sci. USA 89: 11109-11110.

18.Shi, Y. and J.M. Berg. 1995. A direct comparison of the properties of natural and designed zinc-finger proteins. Chem. Biol. 2:83-89.

19.Yokono, M., N. Saegusa, K. Matsushita, and U. Sugiura. 1998. Unique DNA-binding mode of the $\mathrm{N}$-terminal zinc finger of transcription factor Sp1. Biochemistry 37: 6824-6832.

20.Desjarlais, J.R. and J.M. Berg. 1993. Use of a zinc-finger consensus sequence framework and specificity rules to design specific DNA binding proteins. Proc. Natl. Acad. Sci. USA 90:2256-2260.

21.Nakamura, Y., T. Gojobori, and T. Ikemura. 2000. Codon usage tabulated from the international DNA sequence databases: status for the year 2000. Nucleic Acids Res. 28:292.

Received 12 June 2003; accepted 2 September 2003.

Address correspondence to Anna V. Hine, School of Life and Health Sciences, Aston University, Aston Triangle, Birmingham, B4 7ET, UK.e-mail:a.v.hine@aston.ac.uk

\title{
Nitrogenase genes in PCR and RT-PCR reagents: implications for studies of diversity of functional genes
}

\author{
Jonathan P. Zehr, Lori L. Crumbliss, Matthew J. Church, \\ Enoma O. Omoregie, and Bethany D. Jenkins \\ University of California, Santa Cruz, Santa Cruz, CA, USA
}

BioTechniques 35:996-1005 (November 2003)

Studies of the diversity of microorganisms in the environment have been facilitated by use of $P C R$ and reverse transcription PCR (RT-PCR). Inhibition of the PCR by complex sample matrices and low abundance of some target microorganisms require the use of high-sensitivity amplification procedures, involving a large number of cycles or nested PCR methods. Using these methods, we frequently observed contamination of the amplification reagents, including polymerases, by genomic DNA containing nitrogenase (nifH) and $r R N A$ genes. Contaminating genes were sequenced and found to belong to a variety of $r R N A$ clades, but only three major nifH clades. These sequence types included a few nifH sequences reported in previous studies of the environment. Contamination could be reduced by restriction digestion and ultrafiltration of PCR reagents, but efficiency of amplification was also reduced. Our results suggest that studies relying on large numbers of PCR amplification cycles to assess environmental gene diversity should take precautions to assure that clone libaries generated from amplified PCR products are not the result of contaminated PCR reagents.

\section{INTRODUCTION}

The study of the diversity of microorganisms in the environment has been facilitated by the development of DNA and RNA amplification procedures (1). The diversity of microbial assemblages can be investigated by amplification of rRNA genes $(2,3)$ or genes involved in specific metabolic capabilities, such as ammonia oxidation (4), dissimilatory nitrate reduction $(5,6)$, and nitrogen fixation $(7,8)$.

Environmental applications of the PCR are often hampered by inhibition of amplification by the sample matrix, and target microorganisms are often present in extremely low abundance. As a result, high-sensitivity methods such as nested PCR and reverse transcription PCR (RT-PCR) are often used. Target microorganisms often have not been previously cultivated (9-11), making it difficult to determine if PCR-amplified sequences were obtained from the environment or from low-level contamination from sample handling or reagents.

In environmental studies that target previously uncultivated microorganisms, there are many potential sources of contamination with microorganisms from reagents or laboratory surfaces. Genomic DNA contamination of thermal-stable polymerases and other reagents has been reported in rRNA studies (12-14). Contamination often remains problematic even though a number of procedures can be used to eliminate or reduce contamination (12,15-18).

Targeting genes that are not universally distributed among microorganisms, such as nitrogenase, ammonia monooxygenase, or methane monooxygenase $(4,19,20)$, would be expected to be less prone to contamination from laboratory or reagent sources, since these genes may not be present in many of the microorganisms that are typically found in laboratory reagents and enzyme preparations. However, we found that commercial reagents are routinely contaminated with low levels of nitrogenase genes (nifH, encoding the $\mathrm{Fe}$ protein) as well as $16 \mathrm{~S}$ rRNA genes.

\section{MATERIALS AND METHODS}

\section{PCR Reagents}

Only commercial water (nucleasefree; Ambion, Austin, TX, USA) and 
reagents were used for PCRs and for extraction reagent preparation. All labware and reagents, except the polymerase and primers, were treated with UV irradiation in the PCR cabinets prior to use. ART ${ }^{\circledR}$ self-sealing barrier filter pipet tips (Molecular BioProducts, San Diego, CA, USA) were used for dispensing and transferring all liquids and samples.

\section{Clean Room Procedures for PCR}

Dedicated laboratories and automatic pipets were used for each PCR processing step to eliminate contamination with recombinant DNA or PCR products during PCR setup. Reagents were stored in a dedicated freezer in this clean room. Core mixtures for both stages of the nested PCR were prepared in a pre-PCR clean room, which is used only for reagent storage, extraction of environmental samples, and PCR core mixture preparation. All subsequent steps were performed in other laboratories. The PCR core mixtures were prepared in a dedicated UV PCR cabinet (The CleanSpot; Coy Laboratory Products, Grass Lake, MI, USA) in the pre-PCR room. The core mixtures were closed and then transferred to a second UV PCR cabinet in the pre-PCR room dedicated to the addition of genomic DNA or RNA. The tubes were closed and removed from the pre-PCR room to add the positive control. The other tubes were not opened until after the first stage of PCR.

After the first stage, the tubes were transferred to a separate small laboratory dedicated to setting up the nested stage of PCR. Samples (1-3 $\mu \mathrm{L})$ from the first stage of the reaction were transferred, opening a single tube at a time, to the tubes containing the second-stage core mixture. The secondstage core mixture was prepared in the pre-PCR room.

The PCRs, both the first and second stages, were performed in instrumentation laboratories containing the thermal cyclers [Techne ${ }^{\circledR}$ Progene (Techne, Cambridge, UK); GeneAmp ${ }^{\circledR} 5700$ Sequence Detector or the ABI PCR System 9700 (Applied Biosystems, Foster City, CA, USA)]. The tubes were not opened in these laboratories.

\section{PCR and RT-PCR Reagents}

Since our samples from low productivity aquatic systems contain relatively low abundances of the target microorganisms, both RT-PCR and PCR approaches require nested amplification steps. The nested RT-PCRs in this study were performed with the Access RT-PCR system kit (Promega, Madison, WI, USA). Nested PCRs to detect contamination were performed with reagents and enzymes from Promega (Taq DNA polymerase), Takara (ExTaq ${ }^{\mathrm{TM}}$; Madison, WI, USA), BD Biosciences Clontech (TITANIUM ${ }^{\mathrm{TM}}$ Taq; Palo Alto, CA, USA), Ambion (SuperTaq ${ }^{\mathrm{TM}}$ ), and GeneChoice (TaqComplete; Frederick, MD, USA). All nifH primers were synthesized and purified by polyacrylamide gel electrophoresis (PAGE) and high-performance liquid chromatography (HPLC) by New England Biolabs (Beverly, MA, USA). We have found the use of these high-quality primer preparations important for successful application of these particular primers.

The RT-PCR protocol we used had a combined RT and PCR stage involving 40 cycles followed by the second nested PCR stage of 30 cycles. Therefore, in order to have comparable amplification, we also used 40 and 30 cycles for nested PCR tests to test for contamination.

\section{Nested RT-PCR or PCR}

The RT reaction was performed at $48^{\circ} \mathrm{C}$ for $45 \mathrm{~min}$, and then the first stage of the nested PCR (40 cycles) was initiated with the addition of $2.5 \mathrm{U}$ of $\mathrm{Tfl}$ DNA polymerase $\left(1 \mathrm{~min}\right.$ at $94^{\circ} \mathrm{C}, 1 \mathrm{~min}$ at $57^{\circ} \mathrm{C}$, and $1 \mathrm{~min}$ at $72^{\circ} \mathrm{C}$ ). For the first stage of the nested RT-PCR, nifH3 (5'-ATRTTRTTNGCNGCRTA-3') and nifH4 (5'-TTYTAYGGNAARGGNGG-3') primers were added in a 50$\mu \mathrm{L}$ reaction volume containing $28 \mu \mathrm{L}$ diethylpyrocarbonate (DEPC)-treated water, $10 \mu \mathrm{L}$ avian myeloblastosis virus (AMV) $5 \times$ buffer, $1 \mu \mathrm{L}$ AMV reverse transcriptase, and $1 \mu \mathrm{L}$ of sample. For the first stage of the PCR, the same primers were used, and the polymerase, enzymes, and reaction buffers were used as suggested by the manufacturer.

After the first stage (of either RT-PCR 
or PCR), $2 \mu \mathrm{L}$ of the first stage product were added to the second stage of a PCR using the nifH1 and nifH2 primers (nifH1: 5'-TGYGAYCCNAARGCNGA-3'; nifH2: $5^{\prime}$-ADNGCCATCATYTCNCC$\left.3^{\prime}\right)$ (19). Cycling conditions were as for the first stage of PCR described above.

\section{S rRNA Amplification}

To determine if contamination of reagents included genes other than nitrogen fixation genes, experiments were also performed using 16S rRNA primers using Taq DNA polymerase and ExTaq. 16S rRNA primers were synthesized by Integrated DNA Technologies (Coralville, IA, USA). The primers were 5'-ACWCCTACGGGWGGCAGCA-3' [forward primer, Escherichia coli positions 338-357, based on complement of 355R (21)] and 5'-CCCGTCAATTCCTTTGAGTTT$3^{\prime}$ (reverse primer, E. coli positions 926-906). Cycling conditions were 5 min at $94^{\circ} \mathrm{C}$, followed by 35 cycles of $94^{\circ} \mathrm{C}$ for $0.5 \mathrm{~min}, 50^{\circ} \mathrm{C}$ for 0.5 $\min , 72^{\circ} \mathrm{C}$ for $2 \mathrm{~min}$, and a final extension step for $10 \mathrm{~min}$ at $72^{\circ} \mathrm{C}$. The amplification products were cloned and sequenced. Sequences have been submitted to GenBank ${ }^{\circledR}$ under accession nos. AY225105-AY225107 and AY333089-AY33310.

Amplification products (approximately $360 \mathrm{bp}$ long for nifH and about $600 \mathrm{bp}$ for $16 \mathrm{~S}$ rRNA) were visualized on ethidium bromide-stained $0.8 \%$ agarose gels. Amplification products were excised from the gels and cloned into pGEM $^{\circledR}$-T vector (Promega) and grown in $E$. coli JM109 competent cells. The recombinant plasmids were purified using QIAprep ${ }^{\circledR}$ Spin Miniprep kits (Qiagen, Valencia, CA, USA) and screened for inserts by restriction digestion. Inserts were sequenced using Big Dye ${ }^{\mathrm{TM}}$ chemistry on an ABI PRISM ${ }^{\circledR} 310$ or ABI 3100 automated DNA sequencer according to the manufacturer's protocols (all from Applied Biosystems). Representative sequences of nifH groups were sequenced on both strands.

Sequences were edited using GCG software (Wisconsin Package Version 10.3; Accelrys, San Diego, CA, USA) and compared to extant nifH sequences in the databases using a nifH database (22) maintained in ARB phylogenetic database software (23). Phylogenetic trees of nifH DNA sequences containing all closely related sequences and sequences of major representative groups were constructed by neighbor-joining using ARB (http://www. arb-home.de/).

\section{Experiments}

Once contamination was suspected in the reagents, procedures were initiated to attempt to reduce contaminating DNA in reagents by ultrafiltration using disposable centrifugal filter units. Core reagents and water were purified with 300,000, 
$100,000,30,000,10,000$, or 5000 nominal molecular weight limit (NMWL) cartridges (Millipore, Billerica, MA, USA). These could not be used to purify the enzyme preparations or core mixtures with enzyme added, because these filters would retain the enzymes. Ultrafiltration of some of the reagents was found to reduce contamination, but not eliminate it (data not shown), thus restriction diges- tion was also tested to see if contamination could be reduced further.

Restriction digestion (12) was used in conjunction with ultrafiltered aqueous reagents to reduce contamination in reagents and enzymes. After the polymerase was added to the PCR core mixture with enzyme $(2.5 \mathrm{U} / 50$ $\mu \mathrm{L}$ reaction), the $\mathrm{PCR}$ core mixture was subjected to restriction enzyme

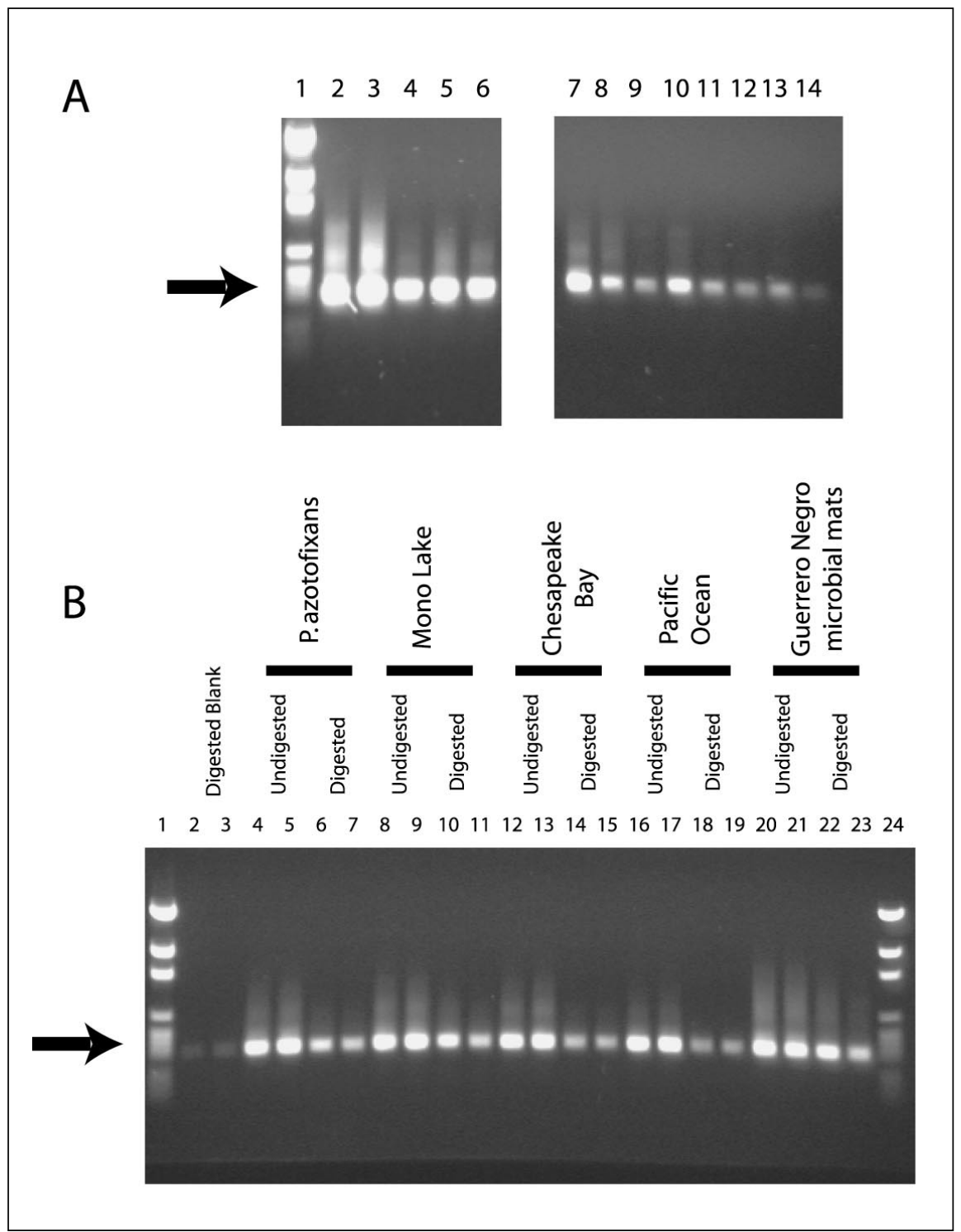

Figure 1. Amplification of nifH in reagent blanks (negative controls) and samples and the effect of ultrafiltration (A) and restriction digestion (B) on reagent contamination. (A) Taq DNA polymerase using unfiltered reagents (lanes 1-6), compared to amplification after ultrafiltering core reagents (lanes 7-14). Core reagents without primer and enzyme were filtered through 10,000 NMWL filter, subsequently filtered through 30,000 NMWL after adding primers, and then the Taq DNA polymerase was added. Lane 1, molecular weight marker pGEM; lanes 2 and 7, positive control Paenibacillus azotofixans; lanes 3 and 8, positive control Guerrero Negro microbial mat; lanes 4, 5, 9, and 10, Pacific Ocean samples; and lanes 6 and 11-14, negative controls (no addition). (B) Reduction of contamination using $A l u \mathrm{I}$ restriction enzyme digestion of core reagents and enzyme prior to amplification of $n i f H$ from DNA samples indicated. Molecular weight markers (pGEM) are in lanes 1 and 24. 
digestion with enzymes that have 4-bp recognition sites. Three enzymes were tested (AluI, DdeI, RsaI), and $A l u \mathrm{I}$ was found to be the most effective. The core reaction was digested for $120 \mathrm{~min}$ with $1.25 \mathrm{U}$ AluI $/ 50-\mu \mathrm{L}$ reaction, and then the restriction enzyme was inactivated at $65^{\circ} \mathrm{C}$ for $25 \mathrm{~min}$.

Environmental samples from Mono Lake, Chesapeake Bay, and the Guerrero Negro microbial mats were processed using restriction digestion (AluI digestion of first stage core mixture with polymerase) and ultrafiltration (30-kDa filtration of core for second stage) of reagents. After amplification, amplification products were cloned and sequenced to see if contaminant sequences were present after digestion of the reaction buffers prior to adding sample DNA.

\section{RESULTS AND DISCUSSION}

For the past several years (20002003), we have often observed contamination of negative control treatments (filtered, nuclease-free water)

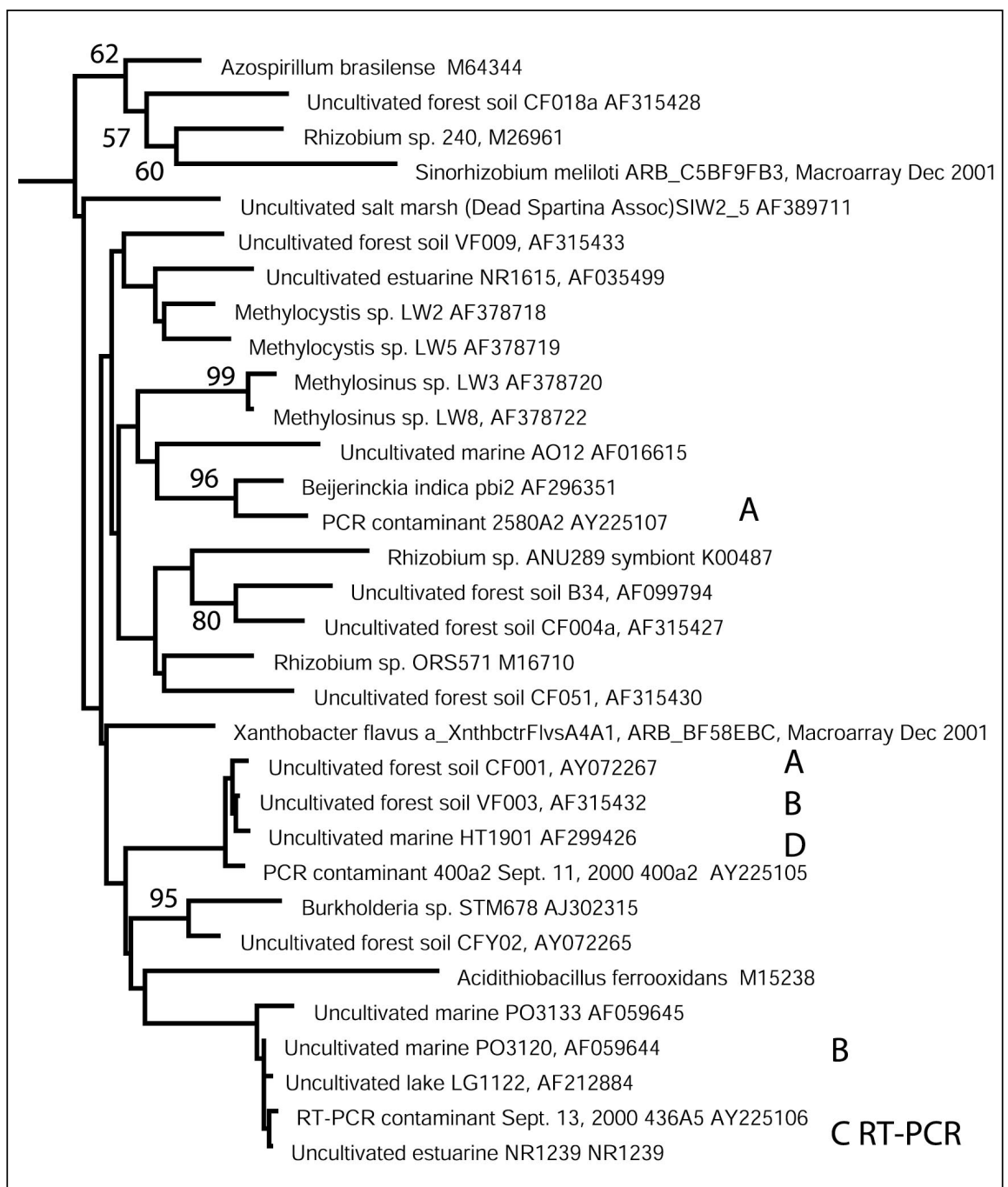

Figure 2. Neighbor joining tree of representative partial nifH sequences obtained from reagent blanks using closely related sequences from GenBank. Sequences $>98 \%$ identical to the indicated contaminant $n i f H$ sequences were recovered in cloned nifH amplification products by six different researchers over the period 2000-2003. Each sequence on tree represents typically 12 clones from each blank that were partially sequenced on one strand for identification purposes. Contaminant sequence type related to soil bacterium VF003 was initially recovered in 2000, recovered sporadically in experiments during 2001 and 2003, and was again found in 2003 in reagents from the same manufacturer (see Figure 3). Bootstrap values greater than $50 \%$ (of 100 replicates) are indicated at the respective nodes of the tree. Letters A, B, C, and D represent different reagent manufacturers. and no-RT (no reverse transcriptase added as control for RT-PCR) controls when applying nested PCR protocols to examine the diversity of nifH-containing microbes in the environment. Amplification in reagent blanks and no-RT controls was intermittent and was associated with nested procedures (PCR and RT-PCR). Sometimes contamination was apparent in no-RT controls, but not in RT samples, probably due to the inhibition of the PCR by the presence of reverse transcriptase (24). Contamination was rarely observed after only 35-40 cycles (a single stage PCR with the nifH primers), but was often evident after nested protocols involving a first stage of 30-40 cycles and a second stage of 30 cycles.

The contamination was observed when experiments were performed in another laboratory in a different building on the University of California, Santa Cruz (UCSC) campus (data not shown) and with enzyme and reagents from different manufacturers. The contamination was reduced when PCR re-

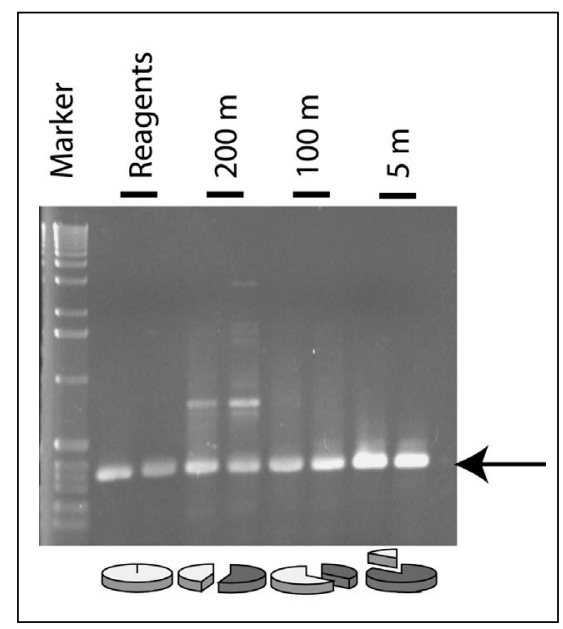

Figure 3. Amplification of nifH from negative controls (commercial reagents) and samples collected in December 2002 from station ALOHA of the Hawaii Ocean Time series. Arrow indicates 359-bp nifH amplification product. Lane 1, molecular weight marker; lanes 2 and 3, reagent blanks (negative controls); lanes 4 and 5 , $200 \mathrm{~m}$ depth; lanes 6 and 7, $100 \mathrm{~m}$ depth; and lanes 8 and $9,5 \mathrm{~m}$ depth. Composition of clone libraries from negative controls (reagents only) and samples from 200,100 , and $5 \mathrm{~m}$ are shown as pie charts below the gel lanes. Grey shading indicates proportion of library composed of contaminant sequences (99\% identical to sequence from uncultivated forest soil bacterium VF003), showing that the blank was entirely composed of the contaminant sequence type. 
agents were filtered through ultrafilters that excluded molecules greater than 100,000 MW (Ultrafree ${ }^{\circledR}$ Centrifugal Filtration Unit, 100,000 NMWL, 0.5 $\mathrm{mL}$ volume; Millipore) (Figure 1A). These ultrafilters should theoretically exclude DNA molecules larger than approximately $150 \mathrm{bp}$ in length, which should exclude the 359-bp product in these PCR experiments.

To further reduce contaminating genomic DNA in enzymes and reaction buffers, restriction enzyme digestion was performed on the PCR core mixtures prior to adding genomic DNA (12). Of the three enzymes tested, Alu I appeared the most effective in reducing amplification in negative controls (Figure 1B). The digestion of PCR core mixtures using $A l u \mathrm{I}$ was also tested with several positive controls and on samples from a variety of environments (Mono Lake, Chesapeake Bay, Pacific Ocean, and the Guerrero Negro microbial mats). Amplification efficiency was reduced in samples treated by restriction digestion (Figure 1B). However, the contaminant sequences (which are sequences $\geq 99 \%$ identical to the uncultivated forest soil bacterium VF003 sequence) were obtained only in clone libraries where the reagents were not treated by digestion. For example, amplification of samples from the Chesapeake Bay with reagents that had not been treated by restriction digestion produced clone libraries that had 5 out of 13 sequences that were 97\%-99 \% identical on the DNA level to the contaminant sequences. However, when the PCR core mixtures were treated by restriction digest with $A l u \mathrm{I}$, none of the contaminant sequences were obtained from clone libraries constructed from these same samples.

The RT-PCR and PCR contaminant amplification products were cloned and sequenced (initially from several different experiments run in February, July, September, and October 2000) to compare to nifH sequences from cultivated nitrogen-fixing microorganisms and sequences previously amplified in our laboratory. In subsequent experiments (involving more than five different researchers over the course of 3 years), clone libraries from blanks were composed of a single sequence type, but the sequence type differed depending upon the manufacturer of the reagents (enzyme kits) used (Figure 2). Two main groups of sequences were obtained that clustered with $\alpha$-proteobacteria nifH sequences (Figure 2). Some of the sequences obtained were virtually identical ( $>98 \%$ identical at nucleotide level) to a few sequences reported from aquatic and soil environments (25-27).

The contaminant sequence types were found in clone libraries from environmental samples, particularly if the sample was from an oligotrophic environment. As an example, in recent experiments involving analysis of samples from the oligotrophic Pacific Ocean, contaminant sequences $(99 \%$ identical to sequences from uncultivated soil bacterium VF003) were found in the clone libraries generated from 5, 100, and $200 \mathrm{~m}$ (Figure 3). However, the percentage of the clone library composed of the contaminant sequences decreased (from $100 \%$ in the blank) as the amplification product derived from the sample increased (Figure 3). The 5-m sample had the strongest amplification, and the contaminant sequences were the smallest fraction of the clone libraries (Figure 3). The contaminant sequences were only rarely recovered from environments with high concentrations of nitrogen-fixing microorganisms (Mono Lake, microbial mats, and the Chesapeake Bay) and present less of a concern in samples from environments with abundant target microorganisms.

Since the contamination was intermittent, obtained from different suppliers, and was reduced only by ultrafiltration or restriction digestion, the most likely and best supported explanation for the source of the contamination was the reagents used for nested PCR and RT-PCR. 16S rRNA genes were also amplified, cloned, and sequenced from negative controls containing only commercial reagents. The sequences of the contaminating 16S rRNA genes showed that there was DNA from di- 
verse contaminating microorganisms as well as human mitochondrial DNA. Sequences greater than $96 \%$ identical (BLAST, www.ncbi.nlm.nih.gov) to 16S rRNA sequences from Acinetobacter, Propionibacterium, Staphylococcus, Actinomyces, human mitochondria, Stenotrophomonas, and Delftia were obtained. Interestingly, Stenotrophomonas was previously reported to be a biofilm contaminant in high purity water systems (28). Some of the sequences were virtually identical to sequences reported from environmental samples, suggesting that contaminant sequences probably have been reported in other studies.

Our results suggest that PCR reagents may contain diverse DNA fragments that include nitrogenase genes. Amplification of reagent blanks with $16 \mathrm{~S}$ rRNA primers, which amplify a larger fragment size than used in our 16S rRNA experiment (approximately $1500 \mathrm{bp}$ ), had reduced levels of contamination after ultrafiltration of reagents, suggesting that contaminating DNA is relatively small (perhaps $<1$ kb) (data not shown).

Ultrafiltration was not completely effective in eliminating contamination, and it cannot be used for purifying enzymes because the molecular mass of the enzyme precluded size exclusion of amplifiable DNA fragments. It may be difficult to completely eliminate DNA contamination by ultrafiltration of reagents, since at least some of the contaminating DNA is degraded DNA fragments. Even using ultrafiltration to purify the reagents and the enzyme, we found DNA sequences 96\%-99\% identical to sequences recovered by amplification, cloning, and sequencing from negative controls (cluster containing sequences from PCR contaminant on Sept 11, 2000, AY225105, and uncultivated forest soil clone VF003 from GenBank) (Figure 2).

Contaminating genomic DNA, which contains a variety of genes in addition to $16 \mathrm{~S}$ rRNA, can be present in commercial reagents. Recent reports indicate that high purity water systems contain biofilms of microorganisms that include nitrogen-fixers (28). Most sterilization purification procedures will not completely eliminate microorganisms (such as filtration with $0.2-\mu \mathrm{m}$ pore size filters) or fragmented DNA (filtration or sterilization). UV treatment, although effective, is not necessarily $100 \%$ effective (12) and is dependent on intensity of irradiance and the geometry and composition of the container. Thus, biofilms in laboratory water supplies can easily result in DNA contamination of water used in reagent preparation, including buffers, enzymes, and oligonucleotides. We found that specific contaminants could reflect sources (manufacturers) of reagents (Figure 2). However, this does not necessarily have to be consistent, as the source biofilms in water supplies (or equipment used in reagent contamination, such as liquid chromatography supplies) undoubtedly change with time (both in level of contamination and composition of microorganisms), and so the connection between supplier and contaminant sequences should not be considered robust.

The low-level contamination does not represent a serious concern for many applications of the PCR, since most studies use lower numbers of PCR cycles or target specific genes or organisms. However, the sporadic nature of contamination due to the high amplification of PCR should raise concern in all studies involving large numbers of amplification cycles, and contaminant sequences are likely to be reported not only in diversity studies of nifH and 16S rRNA genes but in other genes as well.

It should be noted that reagent contamination is often low enough not to be visualized on gels or to appear in a single negative control. Contaminant sequences can still appear as transient sequences in clone libraries, even under these situations, and can appear as sporadic amplification in samples, blanks, and controls, such as the noRT control often used in RT-PCR. However, once contaminant sequence types have been recognized as possible reagent contaminants, they can be eliminated from sequence analysis in diversity studies, unless related microorganisms are also expected to exist in the natural environment.

In conclusion, it is important to be aware of the sequences that may be present in reagents, so that these sequences can be identified in clone libraries. It is hoped that these results will highlight the potential for contamination of amplification libraries and nucleic acid sequence databases with sequences derived from commercial reagents. Perhaps these findings, along with the results of previous studies (12), will encourage manufacturers to find ways of further purifying reagents for environmental and even biomedical applications.

\section{ACKNOWLEDGMENTS}

We thank Barbara MacGregor and Grieg Steward for helpful advice and encouragement. We also thank R. Bidigare and the crew of the Kilo Moana. This research was supported in part by funding by the National Science Foundation (NSF) (MCB-9977892, OCE-9977460, OCE-9981437, OCE-0131762) and the Department of Energy (DOE) Biotechnological Investigations-Oceans Margins Program (BI-OMP).

\section{REFERENCES}

1.Pace, N.R. 1997. A molecular view of microbial diversity and the biosphere. Science 276 : 734-740

2.Giovannoni, S. and S.C. Cary. 1993. Probing marine systems with ribosomal RNAs. Oceanography 6:95-104.

3.Head, I.M., J.R. Saunders, and R.W. Pickup. 1998. Microbial evolution, diversity and ecology - a decade of ribosomal RNA analysis of uncultivated microorganisms. Microb. Ecol. 35:1-21.

4.Rotthauwe, J.H., K.P. Witzel, and W. Liesack. 1997. The ammonia monooxygenase structural gene amoA as a functional marker: molecular fine-scale analysis of natural ammonia-oxidizing populations. Appl. Environ. Microbiol. 63:4704-4712.

5.Braker, G., J. Zhou, L. Wu, A.H. Devol, and J.M. Tiedje. 2000. Nitrite reductase genes (nirK and nirS) as functional markers to investigate diversity of denitrifying bacteria in Pacific Northwest marine sediment communities. Appl. Environ. Microbiol. 66: 2096-2104

6.Scala, D.J. and L.J. Kerkhof. 2000. Horizontal heterogeneity of denitrifying bacterial communities in marine sediments by terminal restriction fragment length polymorphism analysis. Appl. Environ. Microbiol. 66:19801986.

7.Lovell, C.R., M.J. Friez, J.W. Longshore, and C.E. Bagwell. 2001. Recovery and phylogenetic analysis of nifH sequences from diazotrophic bacteria associated with dead aboveground biomass of Spartina alterniflora. Appl. Environ. Microbiol. 67:5308-5314. 
8.Zehr, J.P. and P.J. Turner. 2001. Nitrogen fixation: nitrogenase genes and gene expression. In J.H. Paul (Ed.), Methods in Marine Microbiology. Academic Press, New York.

9.Giovannoni, S.J., T.B. Britschgi, C.L. Moyer, and K.G. Field. 1990. Genetic diversity in Sargasso Sea bacterioplankton. Nature 344:60-63.

10.Methe, B.A., W.D. Hiorns, and J.P. Zehr. 1998. Contrasts between marine and freshwater bacterial community composition: analyses of communities in Lake George, NY and six other Adirondack lakes. Limnol. Oceanogr. 43:368-374

11.Stackebrandt, E., W. Liesack, and B.M. Goebel. 1993. Bacterial diversity in a soil sample from a subtropical Australian environment as determined by $16 \mathrm{~S}$ rDNA analysis. FASEB J. 7:232-236.

12.Corless, C.E., M. Guiver, R. Borrow, V. Edwards-Jones, E.B. Kaczmarski, and A.J. Fox. 2000. Contamination and sensitivity issues with a real-time universal $16 \mathrm{~S}$ rRNA PCR. J. Clin. Microbiol. 38:1747-1752.

13.Schmidt, T.M., B. Pace, and N.R. Pace. 1991. Detection of DNA contamination in Taq polymerase. BioTechniques 11:176-177.

14.Tanner, M.A., B.M. Goebel, M.A. Dojka, and N.R. Pace. 1998. Specific ribosomal DNA sequences from diverse environmental settings correlate with experimental contaminants. Appl. Environ. Microbiol. 64: 3110-3113.

15.Kolman, C.J. and N. Tuross. 2000. Ancient DNA analysis of human populations. Am. J. Phys. Anthropol. 111:5-23.

16.Mifflin, T.E., C.A. Estey, and R.A. Felder. 2000. Robotic automation performs a nested RT-PCR analysis for HCV without introducing sample contamination. Clin. Chim. Acta 290:199-211.

17.Padua, R.A., A. Parrado, J. Larghero, and C. Chomienne. 1999. UV and clean air result in contamination-free PCR. Leukemia 13: 1898-1899.

18.Scherczinger, C.A., C. Ladd, M.T. Bourke, M.S. Adamowicz, P.M. Johannes, R. Scherczinger, T. Beesley, and H.C. Lee. 1999. A systematic analysis of PCR contamination. J. Forensic Sci. 44:1042-1045.

19.Zehr, J.P. and L.A. McReynolds. 1989. Use of degenerate oligonucleotides for amplification of the nifH gene from the marine cyanobacterium Trichodesmium spp. Appl. Environ. Microbiol. 55:2522-2526.

20.Henckel, T., U. Jackel, S. Schnell, and R. Conrad. 2000. Molecular analyses of novel methanotrophic communities in forest soil that oxidize atmospheric methane. Appl. Environ. Microbiol. 66:1801-1808.

21.Amann, R.I., W. Ludwig, and K.-H. Schleifer. 1995. Phylogenetic identification and in situ detection of individual microbial cells without cultivation. Microbiol. Rev. 59: 143-169.

22.Zehr, J.P., B.D. Jenkins, S.M. Short, and G.F. Steward. 2003. Nitrogenase gene diversity and microbial community structure: a cross-system comparison. Environ. Microbiol. 5:539-554.

23.Strunk, O. and W. Ludwig. The ARB-Project: A software environment for sequence data (Munich, Germany) (http://www.arbhome.de).

24.Chandler, D.P., C.A. Wagnon, and H. Bolton, Jr. 1998. Reverse transcriptase (RT) inhibition of PCR at low concentrations of template and its implications for quantitative RT-PCR. Appl. Environ. Microbiol. 64: 669-677.

25.Rosch, C., A. Mergel, and H. Bothe. 2002. Biodiversity of denitrifying and dinitrogenfixing bacteria in an acid forest soil. Appl. Environ. Microbiol. 68:3818-3829.

26.Zehr, J.P., M.T. Mellon, and S. Zani. 1998. New nitrogen fixing microorganisms detected in oligotrophic oceans by the amplification of nitrogenase (nifH) genes. Appl. Environ. Microbiol. 64:3444-3450.

27.Zani, S., M.T. Mellon, J.L. Collier, and J.P. Zehr. 2000. Expression of nifH genes in natural microbial assemblages in Lake George, NY detected with RT-PCR. Appl. Environ. Microbiol. 66:3119-3124.

28.Kulakov, L.A., M.B. McAlister, K.L. Ogden, M.J. Larkin, and J.F. O'Hanlon. 2002. Analysis of bacteria contaminating ultrapure water in industrial systems. Appl. Environ. Microbiol. 68:1548-1555.

Received 19 June 2003; accepted 25 August 2003.

Address correspondence to Jonathan $P$. Zehr, Department of Ocean Sciences and Institute of Marine Science, Earth and Marine Sciences, Bldg A438, University of California, Santa Cruz, 1156 High Street, Santa Cruz, CA 95064, USA. e-mail: zehrj@ucsc.edu 